\title{
Incentive provision and coordination as market functions
}

\author{
John E. Roemer
}

Published online: 30 March 2010

(C) Institut für Arbeitsmarkt- und Berufsforschung 2010

\begin{abstract}
The market has both a coordination function and an incentive function. The first theorem of welfare economics is all about coordination; the principal-agent model is all about incentives. What is the relative importance of the market in carrying out these two functions? While there has been a shift in economic theory in the past thirty years from emphasizing the coordination role to emphasizing the incentive role, it is not clear whether this reflects a new and deeper understanding of the market. Understanding the market's functions, in real economies, may be key for understanding the degree to which redistribution in them is feasible.
\end{abstract}

\section{Anreizbildung und Koordination als Marktfunktionen}

Zusammenfassung Der Markt hat sowohl eine Koordinations- als auch eine Anreizfunktion. Der erste Hauptsatz der Wohlfahrtsökonomik betrachtet die Koordinationsfunktion, die Principal-Agent-Theorie konzentriert sich auf die Anreize. Wie wichtig ist der Markt für die Erfüllung der beiden Funktionen? In den letzten drei Jahrzehnten hat eine Verschiebung in der Wirtschaftstheorie stattgefunden, wodurch die Anreizfunktion des Marktes nun stärker betont wird als die koordinierende Funktion. Es bleibt jedoch unklar, ob diese Entwicklung ein neues und tieferes Verständnis des Marktes widerspiegelt. Die Funktionen des Marktes - in echten Volkswirtschaften - zu verstehen, könnte der

\section{J. E. Roemer (}

Yale University, Dept of Political Science, PO Box 208301, New Haven 06520, CT, USA

e-mail: John.roemer@yale.edu
Schlüssel sein, um zu begreifen, inwieweit in diesen eine Umverteilung möglich ist.

JEL classification J01 · D01 · D30 - D50

\section{Two functions of the market}

The main functions of the market are to provide incentives for economic agents to perform economically useful activity, and to coordinate resource allocation. To be more precise, it is material incentives that the market provides, and that point will be key in what follows.

It is not easy to provide a clean definition that would enable us to distinguish decisively between the incentive and coordination functions of the market, but I think such a distinction exists and is important. Consider the first theorem of welfare economics (FTWE) which is, in my view, a theorem only about the coordination function of the market. Incentive problems are assumed away, as it is simply postulated that firm managers will maximize profits, that workers will supply effort, and so on. Prices, in the FTWE, are simply telling agents what to do. Contrast this with the principal agent model (PAM), which focuses entirely on incentives. Here, prices or contracts or menus are not meant simply to direct agents to do the right thing, but to make them offers they cannot refuse. In the typical PAM, it may well be that the agent knows what the principal wants, but he (the agent) requires a material incentive to induce him to take that action.

Indeed, the change in focus in economic theory, during the past thirty-five years, from general equilibrium theory to contract theory, is associated with a radical change in viewpoint: that the central problem of economics is not one of coordination but one of incentives. Indeed, the old defini- 
tion of economics as the study of the allocation of scarce resources to competing uses is one based upon the coordination view. I conjecture that today's economic theorists would prefer a more mechanism-design sort of definition, putting the emphasis on inducing economic agents to do the right things. I wish to raise the question whether it is really the case that the primary function of markets is the incentive function.

I propose to think of the incentive problem as the problem of encouraging economic agents to expend effort, which will create an economic good (be it an innovation or a labor service). The coordination problem is the one of allocating economic resources to agents (firms and consumers) in an economy: that is, labors of various kinds to firms, other inputs of production to firms, and final goods to consumers. This distinction is imprecise. Is extracting the 'labor' from the 'labor power' of a worker a problem of coordination or incentive? This is a gray area. Roughly speaking, I think of the incentive problem as one of bringing into being economic resources that do not already exist, and the coordination problem as the combining of existing resources into useful outputs. (The labor/labor power distinction focuses on the fact that there is an incentive problem in transforming labor power into labor, as Karl Marx famously emphasized; but that issue is ignored in classical general equilibrium theory and, in particular, in the FTWE.) I wish to explore whether the market is relatively more important as a device for solving one of these problems than the other. Indeed, the principal example upon which I will focus in this paper is the choice of occupation and the effort that is implied by the necessity to train for it.

One of the most salient natural experiments for studying the relative importance of the market in providing coordination and incentives may be the economy of the Soviet Union. Almost everyone now agrees that there were vast inefficiencies in the Soviet economy, primarily due to the system of central allocation and planning, relied upon in lieu of the market. Is it possible to say that the main deficiency suffered due to the market's absence was of coordination, or of proper incentives? Certainly evidence has been offered for both viewpoints. Perhaps the view of the failure of incentives is best summed up in the Soviet joke, "They pretend to pay us and we pretend to work." On the other hand, if we look at the debates that occurred in the 1960s in the USSR about introducing prices, it seems that the main concern was for coordination. In the (Evsei) Liberman debate (Zaleski 1967), economists talked about using prices to decentralize the planning problem; the assumption seems to have been that firm managers wanted to do the right thing, but it was often simply infeasible to do so, lacking prices. Leonid Kantorovich studied and solved the transportation problem, a special case of linear programming, for which he shared the Nobel Prize with Tjalling Koop- mans; the transportation problem is entirely one of coordination.

Going back somewhat further, even Friedrich Hayek - at least the pre-war Hayek- emphasized the coordination function of markets over their incentive function. In his interchange with Oscar Lange on market socialism, he wrote that he was willing to assume that firm managers under socialism were 'loyal and capable (Hayek 1940);' the problem, he said, was that without real competition in real markets, they would never learn the best technologies to use, what goods needed to be supplied, and so on. Planners would be incapable of giving them directions that would guide managers to the right actions, even though, Hayek assumed, they would desire to carry out those actions, if they knew what they were. Even the Hayekian view of the entrepreneur is ambivalent: Do entrepreneurs come up with new ideas because they want to make money, or because they love the game of creation and invention? If the former, then the market is providing incentives; if the latter, it is coordinating! I do not know Hayek's view on entrepreneurs, but Schumpeter's view is clear: entrepreneurs are in it for the love of the game. The money is quite secondary to them ${ }^{1}$. Schumpeter writes that entrepreneurs never finance their own projects; they are a distinct class from investors or capitalists. (This is not quite the same as saying that they are not in it for the money, but the point is related.)

Robert Allen's (2003) recent Soviet economic history suggests that the main problem with the Soviet economy was one of poor coordination, not poor incentives. He writes that, until around 1970, the development strategy in the USSR was straight-forward: move peasants from the farms into the cities to man the factories. This produced industrialization and a rapid rate of growth. But by 1970 or so, the move from farm to factory was complete, and the next problem was to figure out how to innovate and target different sectors' growth, and here the planners made bad mistakes. Allen claims that factory managers pretty much did what they were told to do by planners: there was no major failure of incentive. But when more subtle questions of economic development had to be answered, the lack of participation by thousands of creative economic agents in a decentralized way became $\mathrm{key}^{2}$.

Indeed, before 1970, there was very little criticism by western economists of the Soviet economic model: the main attacks were political. Indeed, many believed that the Soviet economic juggernaut would overtake the west. The formulation of the PAM in 1973 (see Ross 1973) changed

\footnotetext{
${ }^{1}$ See McCraw (2007).

${ }^{2}$ Christian Seidl has suggested to me that risk aversion may have played a significant part in deterring innovation in the Soviet Union, due to the large penalties incurred by failure to realize plans. This, too, could have been especially damaging after the farm-to-factory transition had occurred.
} 
all that: but we must ask, did that model change the way economists interpreted reality (with a good hammer, every problem looks like a nail), or was the view that the Soviet economy suffered from poor incentives based upon a new post-1960s reality?

It would, of course, be extremely interesting to be able to answer this question about the Soviet economy for its own sake. But my principal interest in the question is motivated by my belief that, upon its answer, depends the possibility for, eventually, achieving much more equality of income and wealth than we currently have in market economies, while still using the market mechanism. Roughly speaking, if the market is needed mainly as a coordination device, then it should be possible to separate consumption from earnings without harming efficiency. Markets can be used to coordinate economic activity, and then substantial redistribution can be implemented to reduce inequality of consumption. On the other hand, if the market is needed mainly to provide material incentives, then it is much harder to redistribute without substantial effects on productivity.

Indeed, this could explain why the Nordic countries have implemented a highly egalitarian distribution of income without, apparently, any substantial efficiency costs (see Lindert 2004). This explanation, however, is not Lindert's: he believes that the reason efficiency has been maintained in the Nordic economies is because taxes are designed cleverly, so as not to reduce output. (Capital is taxed relatively lightly, while labor, the immobile factor, is heavily taxed.) But Lindert's is only one interpretation. A second possible interpretation is that effort decisions of economic agents are fairly insensitive to relative earnings, but prices do give people instructions about what to do - where to expend effort.

Let me reiterate one point: the claim that coordination is the main function of the market is not a claim that individuals do not maximize utility. If material incentives are not indispensable, that must be because income is not the most important argument in the preferences of economic agents. The incentives that people have to perform economic activity may not be terribly sensitive to their incomes: they may come from other motivations, such as enjoyment of work, making a social contribution, feeling one's life is productive, demonstrating to others that one is productive, and so on. Again, we may glean clues from the Soviet experience: it does not seem that people in general failed to become educated, although the material benefits to higher education were fairly small. Likewise, Cuba has (or had for many years) the highest literacy rate in Latin America, although surely the returns to education are much higher in capitalist countries in Latin America than in Cuba. It may well still be the case that Cuba's medical establishment is the best in Latin America, although their physicians are surely not very well paid.
I believe the truth is that markets are needed both for incentives and coordination: I am questioning the virtual disappearance of coordination as a market function in recent economic theory. To continue with the Cuban example, the Financial Times notes that Raul Castro's government is planning to diminish the guaranteed level of social provision of foodstuffs to Cubans. Alfredo Jam, head of macroeconomic analysis in the Cuban economic ministry told the FT reporter, "We can't give people so much security with their income that it reduces their willingness to work. We can have equality in access to education and health, but not equality in income. (FT, August 19, 2008)." Evidently, Jam believes that incentives are important.

As a final remark, to note how things have changed in economic theory, consider Hayek's (1945) statement to the American Economic Association, in his 1945 presidential address. That famous address is entitled, "The use of knowledge in society." Hayek's critique of the First Theorem of Welfare Economics is not that it ignores incentives: it is that real markets are needed to find (equilibrium) prices. Indeed, there is no explicit discussion of incentives in this address. It is implicitly assumed that individual agents take actions to increase their profits, but little is made of that. The main point is that knowledge of time and place - local knowledge - is as important as scientific knowledge, and that that kind of knowledge can never be assimilated by a central planning bureau. There is, indeed, no dispute about whether planning is necessary: the question is only whether it can be centralized or must remain decentralized. From my viewpoint, Hayek, at least Hayek before 1950, was a champion of the market as a coordination device.

\section{A general model with differential occupational status and wages}

There are a number of ways one might construct a model to test for the relative importance of markets as coordination and incentive devices. Here I propose a model in which jobs are associated with non-pecuniary attributes, as well as with wages. Workers, who must choose occupations, are concerned with both these attributes and wages and the education required in order to perform the various occupations. Think of these non-wage attributes as comprising, for example, the social status of the occupation, the nature of the work, and the consumers of the product. All these things might well matter to workers who are choosing occupations.

Consider, then, the following model. There is an economy that produces a single good from various kinds of labor. Each kind of labor is called an occupation. If there are three occupations, then the production function for the good is

$$
y=G\left(L_{1}, L_{2}, L_{3}\right)
$$


where $L_{i}$ is employment in occupation $i$. We take $L_{i}$ to be the fraction of the population employed in job $i$, so output is in per capita terms ( $G$ is constant-returns to scale).

An occupation is characterized by two numbers $\left(e_{i}, \sigma_{i}\right)$; $e_{i}$ is the amount of education needed to perform the occupation, and $\sigma_{i}$ denotes non-pecuniary aspect of the occupation that matters to people. In the present model, I assume that $\sigma_{i}$ does not vary across individuals: it is a common value for all workers. (A generalization would relax this assumption.)

The utility function of a worker of type $\gamma$ is

$$
u(x, J ; \gamma)=a \log x+(1-a) \log \sigma_{J}+\gamma \log \left(E-e_{J}\right),
$$

where $x$ is consumption of the good and $J$ is the occupation performed. The parameter $a \in[0,1]$ is a common value for all workers. The parameter $\gamma$ is distributed according to a continuous distribution function $F$ on the non-negative real numbers, associated with a probability measure $\mathbf{F}$ and a density function $f$. We call $\gamma$ a measure of laziness, although this is a misnomer for why people have different values of the parameter. In this example, we will take $J \in\{1,2,3\}$ where we index jobs in order of increasing educational requirement, and we assume that:

$$
e_{1}=0<e_{2}<e_{3}<E .
$$

We make no assumption about the values of $\left\{\sigma_{J}\right\}$ except that they are positive numbers.

Indeed, for simplicity of exposition only, we will assume that $G$ is Cobb-Douglas:

$$
G\left(L_{1}, L_{2}, L_{3}\right)=L_{1}^{\alpha} L_{2}^{\beta} L_{3}^{\delta} \text { where } \alpha+\beta+\delta=1 .
$$

Suppose that $\left(w_{1}, w_{2}, w_{3}\right)$ is a wage vector for the three occupations, and the price of output is one. Then a worker of type $\gamma$ chooses the occupation that satisfies:

$$
J=\underset{j}{\arg \max } u\left(w_{j}, j ; \gamma\right) .
$$

We define a competitive equilibrium:

Definition 1. A vector $\left(w_{1}, w_{2}, w_{3}\right)$ and a distribution of occupations $\left(\hat{L}_{1}, \hat{L}_{2}, \hat{L}_{3}\right)$ comprise a competitive equilibrium when the price of output is one if:

A. (profit maximization)

$$
\left(\hat{L}_{1}, \hat{L}_{2}, \hat{L}_{3}\right)=\underset{\left(L_{1}, L_{2}, L_{3}\right)}{\arg \max } G\left(L_{1}, L_{2}, L_{3}\right)-w \cdot L
$$

B. (worker optimization)

Exactly fraction $\hat{L}_{j}$ of workers choose occupation $j$.

Definition 2. An admissible allocation is a (measurable) assignment of each worker type to an occupation $\Gamma: \mathfrak{R}_{+} \rightarrow\{1,2,3\}$ and an allocation of output to worker types $x: \mathfrak{R}_{+} \rightarrow \mathfrak{R}_{+}$such that

$$
\int x(\gamma) d F(\gamma)=G\left(L_{1}, L_{2}, L_{3}\right),
$$

where $L_{j}=\mathbf{F}\left(\Gamma^{-1}(j)\right)$.

Thus an admissible allocation is denoted $(x(\cdot), \Gamma(\cdot))$.

Definition 3. An admissible allocation is Pareto efficient if there exists no other admissible allocation which increases the utility of a set of agents of positive measure, and decreases the utility of none.

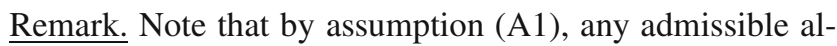
location that produces a positive amount of output, in which all workers receive positive output, strictly Pareto dominates the null allocation where nobody works.

We denote an allocation with positive output as a non-null allocation.

We work with three occupations here, because the model with two occupations is very simple. However, the model with three occupations involves the full complexity of the problem, and generalizes easily to any finite number of occupations.

Theorem 1. If $(\hat{x}, \hat{\Gamma})$ is the admissible allocation associated with a non-null competitive equilibrium $\left(\hat{w}_{1}, \hat{w}_{2}\right.$, $\left.\hat{w}_{3}\right)=\hat{w}$, then it is Pareto efficient.

The proofs of theorems 1 and 2 are in the appendix below.

Theorem 2.

A. If $a \neq 0$, then there exists a non-null competitive equilibrium.

B. If $a=0$ and

$$
\frac{\log \frac{\sigma_{2}}{\sigma_{1}}}{\log \frac{E}{E-e_{2}}} \geq \frac{\log \frac{\sigma_{3}}{\sigma_{2}}}{\log \frac{E-e_{2}}{E-e_{3}}}
$$

then there exists a non-null equilibrium.

\section{Further discussion}

Clearly, the parameter $a$ in the utility function measures the relative importance of non-pecuniary aspects of the occupation to it pecuniary aspect. If $a$ is close to one, then wages are important in motivating occupational choice; if $a$ is close to zero, then non-pecuniary aspects are important. These two cases correspond, roughly speaking, to the cases where the labor market is important as an incentive device, and as a coordinating device, respectively.

Let us take the extreme case when $a=0$. Then wages have no effect on occupational choice. Workers sort themselves into occupations based entirely on their nonpecuniary characteristics. What does the market do? It adjusts real wages so that the profit-maximizing firm demands occupational labor which corresponds exactly to 
what workers have chosen. The market coordinates the firm's occupational demands with those supplied inelastically by workers. There is no incentive problem that the market must solve, as far as workers are concerned. (In this model, I have abstracted away from the problem of firm formation, having chosen to focus on the problem of labor.)

To study the effect of the parameter $a$ on the allocation, it is simplest to work with the two-occupation model. Thus, for now, let us assume that the occupations are characterized by educational qualifications $\left(e_{1}, e_{2}\right)=\left(0, e_{2}\right)$ and by nonpecuniary characteristics $\left(\sigma_{1}, \sigma_{2}\right)$. The production function is $G\left(L_{1}, L_{2}\right)=L_{1}^{\alpha} L_{2}^{1-\alpha}$. The competitive equilibrium will be characterized by a triple $\left(\gamma^{*}, w_{1}, w_{2}\right)$ where the worker of type $\gamma^{*}$ is indifferent between the two occupations, all workers with $\gamma<\gamma^{*}$ choose occupation 2, and all workers with $\gamma>\gamma^{*}$ choose occupation 1. This condition and profit maximization require the equations:

$$
\begin{gathered}
a \log w_{1}+(1-a) \log \sigma_{1}+\gamma^{*} \log E= \\
a \log w_{2}+(1-a) \log \sigma_{2}+\gamma^{*} \log \left(E-e_{2}\right) \\
w_{1}=\alpha\left(\frac{L_{2}}{L_{1}}\right)^{1-\alpha} \\
w_{2}=(1-\alpha)\left(\frac{L_{1}}{L_{2}}\right)^{\alpha} \\
F\left(\gamma^{*}\right)=L_{2} \text { and } 1-F\left(\gamma^{*}\right)=L_{1} .
\end{gathered}
$$

These equations are easily solved for $\left(L_{1}, L_{2}, \gamma^{*}, w_{1}\right.$, $w_{2}$ ); we have

$$
\gamma^{*}=\frac{a \log \left(\frac{1-\alpha}{\alpha} \frac{1-F\left(\gamma^{*}\right)}{F\left(\gamma^{*}\right)}\right)+(1-a) \log \frac{\sigma_{2}}{\sigma_{1}}}{\log \frac{E}{E-e_{2}}},
$$

an equation whose solution gives us $\gamma^{*}$, from which the other variables of the equilibrium can be immediately computed. It is easily computed that

$$
w_{2}>w_{1} \Leftrightarrow \frac{1-\alpha}{\alpha}>\frac{F\left(\gamma^{*}\right)}{1-F\left(\gamma^{*}\right)}
$$

so we may expect this inequality to hold, if this were a realistic economy. Since the inequality in Eq. (4.2) means that $(1-\alpha)\left(1-F\left(\gamma^{*}\right)\right)>\alpha F\left(\gamma^{*}\right)$, Eq. (4.1) immediately implies, if $a>0$, that

$$
w_{2}>w_{1} \Leftrightarrow \gamma^{*}>(1-a) \frac{\log \frac{\sigma_{2}}{\sigma_{1}}}{\log \frac{E}{E-e_{2}}} .
$$

Suppose that we wish to transfer income from the members of occupation 2 to those of occupation 1 . If we impose an income tax at rate $\tau$ on members of occupation 2 and transfer the proceeds to members of occupation 1, what effect will there be at the new equilibrium on the composition of the labor force? The equilibrium with this kind of taxation will be characterized by the following equations:

$$
\begin{gathered}
a \log \frac{(1-\tau) w_{2}}{\left(1+\tau^{\prime}\right) w_{1}}+(1-a) \log \frac{\sigma_{2}}{\sigma_{1}}=\gamma^{*} \log \frac{E}{E-e_{2}} \\
w_{1}=\alpha\left(\frac{L_{2}}{L_{1}}\right)^{1-\alpha} \\
w_{2}=(1-\alpha)\left(\frac{L_{1}}{L_{2}}\right)^{\alpha} \\
F\left(\gamma^{*}\right)=L_{2} \text { and } 1-F\left(\gamma^{*}\right)=L_{1} \\
\tau w_{2} L_{2}=\tau^{\prime} w_{1} L_{1},
\end{gathered}
$$

where $\tau^{\prime}$ is the fraction by which occupation-1 incomes increase (condition (5B) is the budget-balance condition). Since the budget-balance equation (5B) allows us to express $\tau^{\prime}$ in terms of $\tau$, we may write Eq. (1B) as:

$$
\begin{aligned}
& a \log \left[\frac{1-\tau}{1+\frac{1-\alpha}{\alpha} \tau}(1-\alpha) \frac{1-F\left(\gamma^{*}\right)}{F\left(\gamma^{*}\right)}\right]+(1-a) \log \frac{\sigma_{2}}{\sigma_{1}} \\
& =\gamma^{*} \log \frac{E}{E-e_{2}} .
\end{aligned}
$$

We may now see the effect on occupational structure as taxation is imposed. Think of the equilibrium value of $\gamma^{*}$ as an implicit function of $\tau$ as defined by Eq. (4.4). We may compute its derivative and evaluate it at $\tau=0$. We have:

$$
\frac{d \gamma^{*}}{d \tau}(0)=\frac{-a \alpha}{\log \frac{E}{E-e_{2}}+\frac{a f\left(\gamma^{*}\right)}{L_{1} L_{2}}},
$$

where $f$ is the density of $F$ and $\left(\gamma^{*}, L_{1}, L_{2}\right)$ are the equilibrium values at the no-transfer competitive allocation. Thus the change in the occupational structure becomes vanishingly small as $a$ becomes small. This is not a surprise: if pecuniary rewards are relatively unimportant to workers, then income transfers have very little real effects, other than the pure distributional effect.

The comparative statics with respect to changes in $a$ are somewhat interesting. From the equilibrium equations (A1)-(A4), we may view $\gamma^{*}$ as a function of $a$; the derivative at a competitive equilibrium is given by:

$$
\frac{d \gamma^{*}}{d a}=\frac{\log \frac{(1-\alpha) \sigma_{1} L_{1}}{\alpha \sigma_{2} L_{2}}}{1+a f\left(\gamma^{*}\right) \frac{L_{2}}{k L_{1}}}, \quad \text { where } k=\log \frac{E}{E-e_{2}} .
$$


It immediately follows that

$$
\frac{d \gamma^{*}}{d a}<0 \text { as } \frac{(1-\alpha) \sigma_{1} L_{1}}{\alpha \sigma_{2} L_{2}}>1 .
$$

We can re-write this as $\frac{d \gamma^{*}}{d a}<0$ as $\frac{\sigma_{1}}{\sigma_{2}}<\frac{w_{1}}{w_{2}}$.

Recall that an increase in $\gamma^{*}$ implies a decrease in the wage ratio $\frac{w_{2}}{w_{1}}$, because the marginal productivity of occupation-2 workers decreases, and therefore we infer from the last set of inequalities that:

$$
\frac{d\left(\frac{w_{2}}{w_{1}}\right)}{d a}>0 \text { as } \frac{\sigma_{2}}{\sigma_{1}}>\frac{w_{2}}{w_{1}} .
$$

Thus, as the relative concern for non-pecuniary aspects of occupations increases (a decreases) the relative wage can either decrease or increase. As a decreases, the relative wage can increase, if the status ratio $\frac{\sigma_{2}}{\sigma_{1}}$ is low. We cannot a priori associate high wage ratios with a greater relative concern for pecuniary rewards.

We can see why this is the case by writing the equilibrium equation (4.1) as follows:

$$
\begin{aligned}
F^{-1}\left(L_{2}\right)= & \frac{a \log \left(\frac{1-\alpha}{\alpha} \frac{1-L_{2}}{L_{2}}\right)+(1-a) \log \frac{\sigma_{2}}{\sigma_{1}}}{\log \frac{E}{E-e_{2}}} \\
= & \frac{a \log \frac{1-\alpha}{\alpha} \frac{1-L_{2}}{L_{2}} \frac{\sigma_{1}}{\sigma_{2}}+k_{2}}{k_{1}}
\end{aligned}
$$

where $k_{1}$ is a positive constant and $k_{2}$ is a constant. The right-hand side of this equation is a decreasing function of $L_{2}$ and the left-hand side is an increasing function of $L_{2}$; these two curves intersect at the equilibrium value of $L_{2}$. Now increase $a$. The intersection value of $L_{2}$ will increase or decrease, as $\frac{1-\alpha}{\alpha} \frac{1-L_{2}}{L_{2}} \frac{\sigma_{1}}{\sigma_{2}}$ is greater or less than unity. It is obvious that either of these two cases can occur, because we can always choose constants $\left\{\alpha, \sigma_{1}, \sigma_{2}\right\}$ to make the intersection anywhere we choose.

To re-enforce this point, I computed some equilibria for the following example. $F$ is the lognormal distribution with mean 20 and median 15 . $\left(e_{1}, e_{2}, \sigma_{1}, \sigma_{2}, \alpha\right)=$ $(0,10,1,5,0.5)$ and $E=30$. We note that as $a$ decreases, the wage ratio $\frac{w_{2}}{w_{1}}$ increases. (Here, $\frac{\sigma_{2}}{\sigma_{1}}=5$, which is indeed less than the wage ratio in all the equilibria, as we must expect from Eq. (4.6).) Another way to observe the peculiar comparative statics of this economy is that as workers become more concerned with status ( $a$ decreases) the fraction of workers in the high-status occupation decreases. So, in comparing economies, we cannot a priori conclude that ones in which there are more workers in high-status occupations necessarily are ones in which workers care more about status. The false inference one might be inclined to make comes from ignoring the production side of the economy, and how it adjusts efficiently to accommodate changing relative preferences for consumption and status (Table 1).

In Table 2, I present equilibria for the following economy with three occupations: $(\alpha, \beta, \delta)=(0.5,0.35,0.15)$, $\left(e_{1}, e_{2}, e_{3}\right)=(0,10,20),\left(\sigma_{1}, \sigma_{2}, \sigma_{3}\right)=(1,20,30), E=$ 30 , and $F$ the lognormal distribution with mean 20 and median 15 . We see again that as $a$ decreases, inequality of wages increases at the competitive equilibrium.

I propose that it would interesting estimate $a$ for several countries - the US, UK, France, and Sweden, for example. Clearly, if $a$ is small, then redistributive income taxation will
Table 1 An economy with two occupations

Table 2 An economy with three occupations

\begin{tabular}{llllll}
\hline $\mathrm{a}$ & LL1 & LL2 & w1 & w2 & $\gamma^{*}$ \\
\hline 0.8 & 0.911337 & 0.0886627 & 0.155956 & 1.60302 & 5.39121 \\
0.7 & 0.915084 & 0.0849156 & 0.152312 & 1.64137 & 5.29511 \\
0.6 & 0.919244 & 0.0807559 & 0.148198 & 1.68693 & 5.18675 \\
0.5 & 0.923896 & 0.0761038 & 0.143503 & 1.74212 & 5.06325 \\
0.4 & 0.929146 & 0.0708541 & 0.138074 & 1.81063 & 4.92057 \\
0.3 & 0.935136 & 0.0648643 & 0.131685 & 1.89847 & 4.75287 \\
0.2 & 0.942067 & 0.0579328 & 0.123991 & 2.01627 & 4.55109 \\
\hline
\end{tabular}

\begin{tabular}{lllllll}
\hline a & LL1 & LL2 & LL3 & w1 & w2 & w3 \\
\hline 0.5 & 0.890994 & 0.104903 & 0.00410233 & 0.105503 & 0.62726 & 6.8743 \\
0.4 & 0.882358 & 0.114352 & 0.0032907 & 0.105712 & 0.570987 & 8.50362 \\
0.3 & 0.871857 & 0.125771 & 0.00237218 & 0.104682 & 0.507967 & 11.5423 \\
0.1 & 0.8435 & 0.156004 & 0.000495738 & 0.0907429 & 0.343447 & 46.3198 \\
\hline
\end{tabular}


have only a relatively small effect on occupational choice. One source of data for the parameters $\left\{\sigma_{j}\right\}$ is the sociologists' ranking of occupational status (e.g., Miller and Jones 2000). These rankings would have to be converted to cardinal numbers, presumably by assuming a simple functional form for relating rank to cardinal value, and then choosing best fitting parameters for the function.

\section{Conclusion}

Let me apply the distinction I am trying to make between incentives and coordination to Hayek's critique of Oscar Lange's market socialist proposal (Lange 1936). Lange suggested that the Center could propose prices to firm managers, who would respond by reporting the production plans that would equate prices of output to marginal costs, and the planners would then sum up and observe excess demands. Through a procedure of tâtonnement, Lange thought, equilibrium prices could be reached in several iterations. Hayek's (1935) critique was not the modern one, that tâtonnement would perhaps not converge (see Scarf 1960), and it was not that managers would game the planners; it was that (1) there are too many prices to carry out this procedure, (2) managers do not learn their cost functions until they are involved in competition and production, and (3) new commodities and techniques are constantly coming into being in a real market. Some might say that Lange thought the market was important only for coordination, and that Hayek responded that incentive was the key issue.

But from my viewpoint, both Lange and Hayek were thinking of the market as a coordination device. The key point is that Hayek was willing to assume that managers were 'loyal and capable,' that they would not game the system. I agree with Hayek's critique of Lange, but I think that the two views represented different conceptions of what coordination involves. My earlier discussion of Hayek's 1945 AEA address makes this point.

It is not until the principal-agent model, mechanismdesign with a focus on strategy-proofness, and contract theory come into being, that the incentive position is put forth in a strong way in economic theory. Perhaps the theoretically most self-conscious critique of the view that the market is a coordination device is found in the work of Louis Makowski and Joseph Ostroy (1995, 2001). The Makowski-Ostroy critique of general equilibrium theory is very much a critique of Walsrasian equilibrium as a pure coordination view, which minimizes the role of incentives. They challenge the view that rational agents in the typical Walrasian model should be price-takers. Indeed, in their theory, prices do not play a coordination function at all: as they write, prices are what appear after the dust of competitive brawl lifts. For Makowski and Ostroy, a competitive equilibrium is a special case of Walrasian equilibrium - where market conditions make it rational for all agents to take prices as given. Surely, this is an extreme view - it is the polar opposite of the Walrasian auctioneer, who announces prices that everyone docilely accepts. There is, for Makowski and Ostroy, no 'market' as such - but just a large set of individuals bargaining with each other. (See also Makowski and Ostroy (1993), where the authors discuss the market-socialist debate between Hayek and Lange in light of their views, and Roemer (1994) for a history of that debate.)

In reality, both the Walrasian view and the MakowskiOstroy view are too extreme. Surely, prices have, in general, both a coordination and an incentive function.

Let me emphasize, again, that I have not succeeded in conceptualizing generally the distinction between the coordination and incentive functions of the market. It is an empirical question how important the market is for incentives. We are concerned with what motivates people: are they simply concerned with maximizing their wealth, or are they concerned with being respected by others, getting pleasure from their work, following social norms about what kind of work to take, and so on?

One interpretation of the evolution of economic theory from Walrasian equilibrium to contract theory is that economists have simply become more sophisticated: it is progress of the science. Another possibility is that, as capitalism developed from 1870 to 1970 , social norms and individual 'preferences' that emphasized non-materialist values gradually dissolved under the acid influence of the market - an aspect of Marx's commodity fetishism so that, in fact, people in advanced capitalist economies became much more like the rational agents of the GibbardSatterthwaite theorem ${ }^{3}$. Thus, the principal-agent model reflected a new reality, rather than the maturity of economic theory. Of course, with hindsight, contemporary economists look back to Adam Smith and find incentive theory, but that could be simply the historical version of data mining.

\section{Executive summary}

The main functions of the market are to provide incentives for economic agents to perform economically useful activity, and to coordinate resource allocation. To be more precise, it is material incentives that the market provides, and that point will be key in the argument.

\footnotetext{
${ }^{3}$ One aspect of the oft-invoked 'good old days' is of a simpler time when money was instrumental for providing the necessities of life, that made it possible to realize other values, rather than an end in itself.
} 
It is not easy to provide a clean definition that would enable us to distinguish decisively between the incentive and coordination functions of the market, but I think such a distinction exists and is important. Consider the first theorem of welfare economics (FTWE) which is, in my view, a theorem only about the coordination function of the market. Incentive problems are assumed away, as it is simply postulated that firm managers will maximize profits, that workers will supply effort, and so on. Prices, in the FTWE, are simply telling agents what to do. Contrast this with the principal agent model (PAM), which focuses entirely on incentives. Here, prices or contracts or menus are not meant simply to direct agents to do the right thing, but to make them offers they cannot refuse. In the typical PAM, it may well be that the agent knows what the principal wants, but he (the agent) requires a material incentive to induce him to take that action.

Indeed, the change in focus in economic theory, during the past thirty-five years, from general equilibrium theory to contract theory, is associated with a radical change in viewpoint: that the central problem of economics is not one of coordination but one of incentives. Indeed, the old definition of economics as the study of the allocation of scarce resources to competing uses is one based upon the coordination view. I conjecture that today's economic theorists would prefer a more mechanism-design sort of definition, putting the emphasis on inducing economic agents to do the right things. I wish to raise the question whether it is really the case that the primary function of markets is the incentive function.

I argue that the problem of redistributing income to achieve a more equitable allocation of resources is much easier if the market's primary function is coordination than if it is incentive provision. A model is studied in which workers choose occupations, based upon preferences in which occupations have both material (wage) and non-material (status) characteristics. It is proved that an equilibrium exists: a vector of occupational wages at which all labor markets clear. The allocation is Pareto efficient. If workers are concerned mainly with job status, then the market is performing mainly a coordination function; if they are concerned primarily with wages, then it is performing both an incentive and a coordination function. I propose that we attempt to fit this model to various existing economies in order to investigate what workers' relative concerns for status and income are.

\section{Kurzfassung}

Die Hauptfunktionen des Marktes bestehen darin, Anreize für Wirtschaftssubjekte (Agenten) zu bieten, damit diese wirtschaftlich nützliche Tätigkeiten ausführen, und darin, die Verteilung von Ressourcen zu koordinieren. Genauer gesagt bietet der Markt materielle Anreize, und eben dieser Punkt wird für die Argumentation eine zentrale Rolle einnehmen.

Es erweist sich als schwierig, eine einwandfreie Definition zu geben, die es uns ermöglichen würde, eine klare Trennlinie zwischen den Anreiz- und Koordinationsfunktionen des Marktes zu ziehen, aber ich denke, dass eine solche Definition existiert und wichtig ist. Betrachten Sie den ersten Hauptsatz der Wohlfahrtsökonomik, der aus meiner Sicht nichts weiter als ein Satz über die Koordinationsfunktion des Marktes ist. Anreiz-bezogene Probleme werden dabei außer Acht gelassen, da es einfach vorausgesetzt wird, dass Manager den Gewinn maximieren werden, dass Arbeiter ihre Arbeitskraft zur Verfügung stellen werden, usw. Im ersten Hauptsatz der Wohlfahrtsökonomik dienen Preise dazu, den Wirtschaftssubjekten zu sagen, was sie zu tun haben. Vergleichen wir diese Idee mit dem Principal-Agent-Modell, das sich ausschließlich mit Anreizen befasst. Hier sind Preise, Verträge oder eine Auswahl von Verträgen (,Menüs“) nicht lediglich dazu da, Agenten dazu zu bewegen, sich wie gewünscht zu verhalten, sondern dazu, ihnen Angebote zu machen, die sie nicht ablehnen können. In einem klassischen Principal-Agent-Modell kann es durchaus sein, dass der Agent weiß, was der Prinzipal von ihm will, es braucht aber einen materiellen Anreiz, um den Agenten dazu zu bewegen, dies zu tun.

In der Tat hängt die Verlagerung des Schwerpunkts in der Wirtschaftstheorie von der allgemeinen Gleichgewichtstheorie auf die Vertragstheorie, die in den letzten fünfunddreißig Jahren stattgefunden hat, mit einem radikalen Perspektivwechsel zusammen: Das zentrale Problem der Ökonomik ist nicht das der Koordination, sondern das der Anreizsetzung. Die alte Definition der Ökonomie als die Untersuchung der Allokation von knappen Ressourcen an miteinander konkurrierende Verwendungszwecke beruht auf der Betonung der Koordinationsfunktion. Ich vermute, dass die Wirtschaftstheoretiker von heute eine eher Mechanismus-Design-orientierte Definition bevorzugen würden, welche den Fokus darauf legt, dass Agenten dazu gebracht werden, das „Richtige“ zu tun. Doch ich möchte die Frage stellen, ob die primäre Funktion des Marktes tatsächlich darin besteht, Anreize zu bieten.

Ich argumentiere, dass das Problem der Umverteilung von Einkommen, um eine gerechtere Verteilung von Ressourcen zu erlangen, sich wesentlich einfacher gestaltet, wenn man dem Markt eine koordinierende statt eine anreizbildende Primärfunktion zuschreibt. Dabei wird ein Modell betrachtet, in dem Arbeitnehmer ihre Berufe aufgrund eigener Vorlieben und mit Hinblick darauf auswählen, welche Berufe sowohl materielle (Vergütung) und nicht-materielle (Status) Eigenschaften haben. Es wird bewiesen, dass es ein Gleichgewicht gibt: ein Vektor der 
Entlohnungen, bei dem alle Arbeitsmärkte geräumt werden. Die Verteilung ist Pareto-effizient. Wenn Arbeitnehmern hauptsächlich der Jobstatus wichtig ist, erfüllt der Markt vorwiegend eine Koordinationsfunktion. Wenn ihnen aber primär die Vergütung wichtig ist, erfüllt der Markt sowohl eine Koordinations- als auch eine Anreizfunktion. Ich schlage vor, dass wir versuchen, dieses Modell an verschiedene bestehende Volkswirtschaften anzupassen, um zu untersuchen, wie wichtig den Arbeitnehmern jeweils ihr Status und ihr Einkommen sind.

\section{Appendix: Proofs of theorems}

\section{Proof of Theorem 1:}

1. Suppose the claim were false, and let $(x, \Gamma)$ be an admissible allocation which Pareto dominates $(\hat{x}, \hat{\Gamma})$. Indeed, we suppose that every worker is strictly better off in the dominating allocation, to simplify the argument.

2 . We define nine possible groups of worker; group $(i, j)$ are those worker types for whom $\hat{\Gamma}(\gamma)=i$ and $\Gamma(\gamma)=j$. For workers in any group $(i, i)$ it must be that

$$
x(\gamma)>\hat{w}_{i}
$$

for these workers are better off in the dominating allocation than at the equilibrium allocation.

Now consider a worker in a group $(i, j), j \neq i$. It must be that;

$$
x(\gamma)>\hat{w}_{j}
$$

because at the competitive equilibrium, a member of this group chooses occupation $i$, which was therefore at least as good for him as occupation $j$, and in the new allocation he is better off than he was at equilibrium in occupation $i$. It therefore follows that

$$
(\forall(i, j))\left(\gamma \in(i, j) \Rightarrow x(\gamma)>\hat{w}_{j}\right) .
$$

Because by hypothesis the equilibrium is non-null, it follows that the allocation $(x, \Gamma)$ is non-null, and thus for each $j \in\{1,2,3\}$ there is an $i$ such that $(i, j) \neq \varnothing$ (that is, all occupations are occupied at the allocation $(x, \Gamma)$, or it could not possibly P-dominate $(\hat{x}, \hat{\Gamma})$.)

3. Consider the group formed by the union $(1,1) \cup(2,1) \cup$ $(3,1)$. These are the workers who are employed in occupation 1 at the allocation $(x, \Gamma)$. For these workers, $x(\gamma)>\hat{w}_{1}$. Likewise, for workers in the groups $(1, j) \cup$ $(2, j) \cup(3, j)$, for $j=2,3$, we have $x(\gamma)>w_{j}$. But the group $(1, j) \cup(2, j) \cup(3, j)$ comprises exactly the workers assigned occupation $j$ in $(x, \Gamma)$. Therefore, at the wage vector $\hat{w}$, the firm could have hired workers in the occupational structure $\Gamma$, paid them the equilibrium wages, and have a positive amount of output left over. Therefore, it could have produced positive profits at wages $\hat{w}$, a contradiction to profit maximization at the competitive equilibrium, since profits at the competitie equilibrium are zero, because $G$ exhibits constant returns to scale.

This contradiction proves the theorem.

\section{Proof of Theorem 2:}

Part A:

1. Denote the simplex $\left\{\left(L_{1}, L_{2}, L_{3}\right) \mid 0 \leq L_{i} \leq 1, \sum L_{i}=1\right\}$ $=\Delta$. The three vertices of the simplex are $(0,0,1),(0,1,0)$, and $(1,0,0)$. Denote the set consisting of the simplex minus its vertices by $\tilde{\Delta}$.

2. Define the following three functions, which map $\tilde{\Delta}$ into the extended real line:

$$
\begin{aligned}
A(L) & =\frac{a \log \frac{\beta L_{1}}{\alpha L_{2}}+(1-a) \log \frac{\sigma_{2}}{\sigma_{1}}}{\log \frac{E}{E-E_{2}}} \\
B(L) & =\frac{a \log \frac{\delta L_{1}}{\alpha L_{3}}+(1-a) \log \frac{\sigma_{3}}{\sigma_{1}}}{\log \frac{E}{E-E_{3}}} \\
C(L) & =\frac{a \log \frac{\delta L_{2}}{\beta L_{3}}+(1-a) \log \frac{\sigma_{3}}{\sigma_{2}}}{\log \frac{E-e_{2}}{E-E_{3}}} .
\end{aligned}
$$

Note that these functions are well-defined (with range the extended reals) and continuous on $\tilde{\Delta}$. (In particular, the three functions are well-defined on the edges of $\tilde{\Delta}$.)

3. We next note that for all $L \in \tilde{\Delta}, B(L)$ lies between $A(L)$ and $C(L)$. Write these three expressions schematically as:

$$
\begin{aligned}
& A(L)=\frac{a R+(1-a) S}{W}, \\
& C(L)=\frac{a T+(1-a) V}{Z}, \\
& B(L)=\frac{a(R+T)+(1-a)(S+V)}{(W+Z)},
\end{aligned}
$$

where $R=\log \frac{\alpha L_{2}}{\beta L_{1}}$, etc.

Note by assumption (A1) that $W$ and $Z$ are positive numbers.

We have:

$$
\begin{aligned}
B(L) & =\frac{A(L) W+C(L) Z}{W+Z} \\
& =\frac{W}{W+Z} A(L)+\frac{Z}{W+Z} C(L),
\end{aligned}
$$

which proves that $B(L)$ lies between $A(L)$ and $C(L)$. 
4. Now define the mapping $\Phi: \tilde{\Delta} \rightarrow \Delta$ as follows:

$$
\begin{aligned}
& \Phi_{1}(L)=1-F(\max [A(L), B(L)]) \\
& \Phi_{2}(L)=F(\max [A(L), B(L)])-F(\min [B(L), C(L)]) . \\
& \Phi_{3}(L)=F[\min [B(L), C(L)])
\end{aligned}
$$

There are two cases to consider, according to step 4:

$$
\begin{aligned}
& \text { case 1: } A(L) \geq B(L) \geq C(L) \\
& \text { case 2: } A(L) \leq B(L) \leq C(L)
\end{aligned}
$$

In case 1, we have max $[A(L), B(L)]=A(L), \min [B(L)$, $C(L)]=C(L)$, and it follows that $\Phi_{1}(L)=1-A(L)$, $\Phi_{2}(L)=F(A(L))-F(C(L)), \Phi_{3}(L)=F(C(L))$ and so $\sum \Phi_{i}(L)=1$. In case 2 , we have $\Phi_{1}(L)=1-F(B(L))$, $\Phi_{2}(L)=0, \Phi_{3}(L)=F(B(L))$. Therefore, $\Phi$ maps $\tilde{\Delta}$ into $\Delta$. Indeed, $\Phi$ is continuous and single-valued on $\tilde{\Delta}$.

5. We now extend $\Phi$ to the vertices of $\Delta$. Define:

$$
\begin{aligned}
& \Phi(0,0,1)=\{(x, 1-x, 0) \mid 0 \leq x \leq 1\} \\
& \Phi(0,1,0)=\{(x, 0,1-x) \mid 0 \leq x \leq 1\} \\
& \Phi(1,0,0)=\{(0, x, 1-x) \mid 0 \leq x \leq 1\} .
\end{aligned}
$$

Thus $\Phi: \Delta \rightarrow \rightarrow \Delta$, and $\Phi$ is non-empty, convex valued. To show that $\Phi$ is upper hemi-continuous, we need only check its behavior at the vertices.

To this end, consider the vertex $(0,0,1)$, and take any sequence $\left(L_{1}^{i}, L_{2}^{i}, L_{3}^{i}\right) \rightarrow(0,0,1)$. Because $a>0$, $B\left(L^{i}\right) \rightarrow-\infty$ and $C\left(L^{i}\right) \rightarrow-\infty$. Now we can choose a subsequence of the given sequence such that $\frac{L_{1}^{i}}{L_{2}^{i}} \rightarrow k$, for some $k$ in the extended reals (this is always possible). Denoting this subsequence again by $\left\{L^{i}\right\}$, we have that

$$
A\left(L^{i}\right) \rightarrow \frac{a \log \frac{\beta k}{\alpha}+(1-a) \log \frac{\sigma_{2}}{\sigma_{1}}}{\log \frac{E}{E-e_{2}}}=x^{*} \in[-\infty, \infty] .
$$

It follows that $\Phi_{3}\left(L^{i}\right) \rightarrow 0, \Phi_{2}\left(L^{i}\right) \rightarrow 1-F\left(x^{*}\right)$, $\Phi_{1}\left(L^{i}\right) \rightarrow F\left(x^{*}\right)$. Thus $\lim \Phi\left(L^{i}\right) \in \Phi(0,0,1)$, and so $\Phi$ is u.h.c. at $(0,0,1)$. Similar arguments show that $\Phi$ is u.h.c. at the other two vertices as well.

6. By Kakutani's fixed point theorem, it follows that $\Phi$ possesses a fixed point, denoted $\hat{L}=\left(\hat{L}_{1}, \hat{L}_{2}, \hat{L}_{3}\right)$. We show that this fixed point must lie in the interior of $\Delta$. By construction, it is obvious that $\hat{L}$ cannot be a vertex. Suppose, now, that $\hat{L}$ were on an edge: say it is of the form $\left(0, L_{2}, 1-L_{2}\right)$. Then, since $a>0, A(L)=-\infty, C(L)$ is finite, and $B(L)=-\infty$. Therefore $\Phi\left(0, L_{2}, 1-L_{2}\right)=$ $(1,0,0)$, so this is not a fixed point. Similar arguments show that the fixed point cannot lie on any edge, and so all its coordinates are positive.

7. Define the positive vector $\hat{w}$ as follows:

$$
\hat{w}_{1}=\frac{\alpha G(\hat{L})}{\hat{L}_{1}}, \quad \hat{w}_{2}=\frac{\beta G(\hat{L})}{\hat{L}_{2}}, \quad \hat{w}_{3}=\frac{\delta G(\hat{L})}{\hat{L}_{3}} .
$$

Note that if $\hat{w}$ is a wage vector (and the price of output is one), then $\hat{L}$ is the profit-maximizing labor demand for the firm.

Which workers will choose occupation 1 at $\hat{w}$ ? For this to occur, it must be that

$$
u\left(w_{1}, 1 ; \gamma\right)>\max \left[u\left(w_{2}, 2 ; \gamma\right), u\left(w_{3}, 3 ; \gamma\right)\right]
$$

which expands, using Eq. (1), to yield:

$$
\gamma \text { chooses } J_{1} \text { when } \gamma>\max [A(\hat{L}), B(\hat{L})] \text {. }
$$

In like manner, it can be shown that

$$
\begin{aligned}
& \gamma \text { chooses } J_{2} \text { when } \\
& \min [B(\hat{L}), C(\hat{L})]<\gamma<\max [A(\hat{L}), B(\hat{L})]
\end{aligned}
$$

and

$$
\gamma \text { chooses } J_{3} \text { when } \gamma<\min [B(\hat{L}), C(\hat{L})] .
$$

Suppose that 'case 1' holds, and indeed $A(\hat{L})>B(\hat{L})>$ $C(\hat{L})$. Then the mass of workers who choose job 1 is $1-F(A(\hat{L}))$, the mass of workers choosing job 2 is $F(A(\hat{L}))-F(C(\hat{L}))$, and the mass of workers choosing job 3 is $F(C(\hat{L}))$, and all these masses are of positive measure. Now, invoking the fact that $\hat{L}$ is a fixed point of $\Phi$, we see that the labor demand equals the labor supply for each occupation. Thus $(\hat{w}, \hat{L})$ is a non-null competitive equilibrium.

The other possibility under case 1 is that $A(\hat{L})=$ $B(\hat{L})=C(\hat{L})$. (There are the only two possibilities.) In this case, all workers are indifferent among all jobs, and so the labor supply at the given wage vector is the entire simplex; a fortiori, we have a competitive equilibrium. It is left to consider the possibility that 'case 2' holds, i.e., that $C(\hat{L})>B(\hat{L})>A(\hat{L})$. But then, by step 4 , $\Phi_{2}(\hat{L})=0$, contradicting the fact that $\hat{L}$ is interior. Thus case 2 cannot occur.

to Part A.

\section{Part B:}

(Note: The argument of step 4 above does not hold if $a=0$, because it would not follow that $B\left(L^{i}\right)$ and $C\left(L^{i}\right)$ converge to $-\infty$.)

8. We now suppose that $a=0$ and the inequality in Part B holds. Then we have for all $L \in \tilde{\Delta}$,

$$
\begin{gathered}
A(L)=\frac{\log \frac{\sigma_{2}}{\sigma_{1}}}{\log \frac{E}{E-e_{2}}} \equiv A^{*} \\
C(L)=\frac{\log \frac{\sigma_{3}}{\sigma_{2}}}{\log \frac{E-e_{2}}{E-e_{3}}} \equiv C^{*} .
\end{gathered}
$$




$$
B(L)=\frac{\log \frac{\sigma_{3}}{\sigma_{1}}}{\log \frac{E}{E-e_{3}}} \equiv B^{*}
$$

9. Let the inequality (A2) be strict. Then we have $A(L)>C(L)$ for any $L$ and hence (since betweeness still holds), $A(L)>B(L)>C(L)$. Thus

$$
\begin{aligned}
& \text { for any } L \in \tilde{\Delta}, \\
& \Phi(L)=\left(1-F\left(A^{*}\right), F\left(A^{*}\right)-F\left(C^{*}\right), F\left(C^{*}\right)\right),
\end{aligned}
$$

and all three components are positive. Define

$$
\left(\hat{L}_{1}, \hat{L}_{2}, \hat{L}_{3}\right)=\left(1-F\left(A^{*}\right), F\left(A^{*}\right)-F\left(C^{*}\right), F\left(C^{*}\right)\right) .
$$

Then $\hat{L}$ is a strictly positive fixed point of $\Phi$. Defining $\hat{w}$ by Eq. (1) again shows that $(\hat{w}, \hat{L})$ is a C.E.

10. On the other hand, let (A2) hold with equality. Then all workers are indifferent among the three occupations, for any wage vector. Hence any positive wage vector will induce a profit-maximizing demand for labor which lies in the supply of labor correspondence, and hence comprises a C.E.

11. However, if (A2) were false, there is no non-null C.E. For in this case, we would have $C^{*}>B^{*}>A^{*}$ and $\Phi(L) \equiv\left(1-F\left(B^{*}\right), 0, F\left(B^{*}\right)\right)$ for all $L \in \tilde{\Delta}$. Hence the only fixed point entails zero labor in occupation 2 , and therefore zero output.

\section{References}

Allen, R.: From Farm to Factory: A Reinterpretation of the Soviet Industrial Revolution. Princeton University Press, Princeton (2003)

Hayek, F.: The nature and history of the problem. In: Hayek F.A. (ed.) Collectivist Economic Planning. George Routledge \& Sons, London (1935)
Hayek, F.: Socialist calculation: The competitive 'solution.' Economica 7 (new series), 125-149 (1940)

Hayek, F.: The uses of knowledge in society. Am. Econ. Rev. 35, 519-530 (1945)

Lange, O.: On the economic theory of socialism. In: Lippincott B. (ed.) On the Economic Theory of Socialism. University of Minnesota Press, Minneapolis (1956, 1936)

Lindert, P.: Growing Public. Cambridge University Press, New York (2004)

Makowski, L., Ostroy, J.: In: Bardhan, P., Roemer, J. (eds.) Market Socialism: The Current Debate. Oxford University Press, New York (1993)

Makowski, L., Ostroy, J.: Appropriation and efficiency: A revision of the first theorem of welfare economics. Am. Econ. Rev. 85, 808-827 (1995)

Makowski, L., Ostroy, J.: Perfect competition and the creativity of the market. J. Econ. Lit. 39, 479-536 (2001)

McCraw, T.: Prophet of Innovation: Joseph Schumpeter and Creative Destruction. Harvard University Press, Cambridge (2007)

Miller, J., Jones, F.: The ANU2_3 scale: A revised occupational status scale for Australia. J. Sociol. 36, 64-80 (2000)

Roemer, J.: A Future for Socialism. Harvard University Press, Cambridge (1994)

Ross, S.: The economic theory of agency. The principal's problem. Am. Econ. Rev. 134-139 (1973)

Scarf, H.: Some examples of global instability of the competitive equilibrium. Int. Econ. Review 1, 157-172 (1960)

Zaleski, E.: Planning Reforms in the Soviet Union 1962-66. University of North Carolina Press, Chapel Hill (1967)

John Roemer is the Elizabeth S. and A. Varick Stout Professor of Political Science and Economics at Yale University. His current work concerns distributive justice, political economy, and the relationship between them. Recent books are Racism, Xenophobia, and Redistribution (Harvard UP, 2007), Democracy, education and equality (Cambridge UP, 2006), Political Competition (Harvard UP, 2001), Equality of Opportunity (Harvard UP, 1998), Theories of distributive justice (Harvard UP, 1996), and A future for socialism (Harvard UP, 1994).

His main current project is on distributive ethics in the presence of global warming. He is a fellow of the Econometric Society, the American Academy of Arts and Sciences, a corresponding fellow of the British Academy, and a past fellow of the Guggenheim and Russell Sage Foundations.

E-mail: John.roemer@yale.edu 